\title{
A Case Study of CPS Energy’s Management of Disruptive Forces
}

\author{
John Soltau \\ School of Professional Studies, University of the Incarnate Word \\ San Antonio, Texas, USA \\ E-mail: soltau@uiwtx.edu \\ Ryan Lunsford \\ School of Professional Studies, University of the Incarnate Word \\ San Antonio, Texas, USA \\ E-mail: lunsford@uiwtx.edu
}

Received: Oct. 23, 2017 Accepted: Nov. 5, $2017 \quad$ Published: Nov. 15, 2017

doi:10.5296/csbm.v4i2.12127ＵRL: http://dx.doi.org/10.5296/csbm.v4i2.12127

\begin{abstract}
Two major forces continue to drive disruption in the utility space; technological innovation in the form of distributive energy resources (DER), and energy efficiency/demand response (EE/DR). These forces drive down demand which, in turn, leads to decreased revenues for utility companies. As a result, the utility responds by seeking higher rates, which decreases demand and increases economic incentive for DER and EE/DR (Kind, 2013). These two disruptions continue their influence as these increased rates lead to lower customer satisfaction levels, incentivizing the adoption of additional DER and EE/DR products, perpetuating the cycle. As a municipal monopoly CPS Energy (CPSE) faces a number of real threats and opportunities as they ride this wave of disruption. This case study will analyze the impact of the DER and EE/DR forces on CPSE and their risks.
\end{abstract}

Keywords: Electric Utilities, Disruptive Forces, Distributed Energy Resources, Energy Efficiency, Demand Response 


\section{Introduction}

For more than half a century, the United States (US) electrical utility industry experienced relatively little change. Focused on economies of scale to provide reliable and affordable power across the US, the industry developed a risk adverse culture that refined processes and muted innovation (Kind, 2013). However, towards the end of the 20th century, a sequence of events occurred that highlighted the fragility of US energy supply. The oil embargo of the 1970's, an awakening environmental consciousness to carbon pollution in the 1980's, market deregulation and subsequent competition in the 1990's, and technological advancements of the 2000's all lead to increased consumerism in the industry. This once sleeping industry was rudely awakened and now sits on the edge of a disruptive revolution which has the potential to send the traditional utility industry into a death spiral (Kind, 2013).

Two major forces drive disruption in the utility space; technological innovation in the form of distributive energy resources (DER), and energy efficiency/demand response (EE/DR). These forces drive down demand which, in turn, leads to decreased revenues for utility companies. A vicious spiral is created where higher rates and lower customer satisfaction incentivizes more DER and EE/DR, leading to less demand which forces the utility to raise rates to meet regulation requirements, causing the spiral to continue. As a municipal monopoly CPS Energy (CPSE) faces a number of real threats and opportunities as they ride this wave of disruption. This case study will analyze the impact of the DER and EE/DR forces on CPSE and will provide recommendations for them to successfully position themselves.

\section{Background}

Following the first large-scale power generation facility built in 1895, the demand for electricity grew as the US economy matured and realized increased levels of sophistication as witnessed by individual household standard of living increases and macro-level economic growth. By the 1920's almost all of the US was connected to a grid of generation facilities, electrical transmission, and distribution lines powering industry and, the average, working-class house (Kwoka, 2008). As economic growth and quality of living became increasingly connected to electricity, the Federal Government supported initiatives for universal access reaching into rural communities (Hausman \& Neufeld, 2011). The rising demand required larger generation plants and their associated infrastructure of transmission and distribution lines to transport the electricity to the increasing number of factories, businesses, and homes (Kwoka, 2008). These large-scale construction projects required vast amounts of capital with long return periods leading early holding companies to utilize their economies of scale to minimize risk by manipulating rates and suppressing competition (Hausman \& Neufeld, 2011).

The expectation of an accessible, affordable and reliable electrical power grid has led the industry to three foundational dynamics that limit traditional supply and demand markets (Hausman \& Neufeld, 2011). First, the need for universal access, even to areas that are not economically beneficial for the energy company. Second, the nature of electrical grid requires the same amount of electricity to be used as it is generated due to no large-scale means of storage (Kind, 2013). If generation does not meet consumption, the frequency of the grid will 
osculate off the standard of $60 \mathrm{~Hz}$ causing equipment and systems to fail, potentially causing a ripple effect that will shut down all or part of a grid causing "black outs" (Saha, 2003). And third, foundational dynamic of the electrical industry is to achieve economies of scale, electric utilities historically had to invest large amounts of capital in long term projects to generate and transmit their product. Large power plants and grid projects typically have 30-year return on investment periods, putting the investors at substantial risk (Kind, 2013). These three factors favored large centralized electrical utilities as power lines spread across the US (Hausman \& Neufeld, 2011).

These elements led to large holding companies in the early 20th century owning a majority of the electrical generation across the US in an attempt to decrease risk by spreading out demand variance across large territories (Hausman \& Neufeld, 2011). Due to the outcry over market manipulation and rising rates, Congress enacted the Public Utility Holding Company Act (PUHCA) of 1935 and forced holding companies, that managed about $75 \%$ of the electrical generating capacity, to break up, and gave localized utilities a sanctioned monopoly over specific territories with the purpose of providing all US citizens with access to reliable and affordable power, while ensuring investors a small but low risk return (Hausman \& Neufeld, 2011; US House of Representatives, 1935).

Over the next 40 years the electrical industry was in its golden age as demand continued to increase, funding larger capital projects and infrastructure development (Hausman \& Neufeld, 2011). Then, in 1970's, the industry felt its first tremor of disruption as early entrance into the nuclear generation field had some catastrophic effects and the OPEC Oil Crisis increased the volatility of prices (Hausman \& Neufeld, 2011). This led to the Department of Energy being created and the Federal Energy Regulatory Commission (FERC) was given jurisdiction over interstate gas and electrical markets with the goal of diversifying and stabilizing a more market based electrical industry.

The 1990's saw a continuation of movement towards deregulation and competition as public and political pressure led to increased consumer choice and competition. Congress passed the National Energy Policy Act (NEPA) in 1992 which allowed power producers to compete on the wholesale markets, essentially breaking up the large vertically aligned utilities (Kwoka, 2008). In 1995, FERC Order Number 888 furthered deregulation by requiring all transmission lines be open access for all power producers as a conduit for open markets (Kim, n.d.). FERC order Number 2000 in 1999 established a partnership with regional transmission organizations (RTO) and independents system operators (ISO) who locally managed electrical markets and grid reliability (FERC, 1999). These orders started a trend of regulation and breaking up of electrical utility monopolies across the Country.

\subsection{Electrical Reliability Council of Texas (ERCOT)}

Following the NEPA in 1995, wholesale power in Texas was deregulated by the Texas Legislature with the public Utility Regulatory Act, allowing for competitive wholesale pricing and markets (ERCOT, n.d.). The Electrical Reliability Council of Texas (ERCOT) was established in 1977 and became the Nation's first ISO in 1996 when it was given the jurisdiction to create and manage electric markets (ERCOT, n.d.). ERCOT is governed by a 
board of directors with oversight provided by the Public Utility Commission of Texas and the Texas Legislature (ERCOT, n.d.). Their four primary objectives are: system reliability, wholesale market settlement, retail switching for consumer choice, and open access to transmission ("ERCOT: About Us," n.d.). The Texas Legislature voted in 1999 to deregulate the retail electric market and allow consumer to have choice, which took effect in 2002 with an exemption for publicly owned power companies such as CPSE (Potamac Economics, 2016). In 2016, ERCOT had some of the lowest electrical rates in the Nation and $85 \%$ of customers had a choice in their retail power provider (ERCOT, n.d.).

\subsection{Texas Hill Country: San Antonio}

Founded in 1718, San Antonio, Texas spent its first 120 years under Spanish and Mexican control and was a central location for trade and missionary work. Following Texas independence in 1837 and then statehood in 1840, San Antonio worked to become a modern city with the railroad reaching it in 1877 and widespread electrical access in 1883 ("Visit San Antonio," n.d.). Through the 20th century San Antonio continued to grow spurred by the central role it took in trade with Mexico and an increasing military presence " Visit San Antonio," n.d.). Nicknamed "Military City USA" over 132,000 service personnel train at Joint Base San Antonio each year and San Antonio Military Medical Center (SAMMC), the Army's largest in-patient hospital ("Visit San Antonio,” n.d.). Building off the strong military presence, San Antonio is growing into a hub of cyber security and medical research, giving the City a bright outlook. San Antonio currently is the seventh largest City in the US and has a population near 1.5 million (Census Bureau: Quick Facts, n.d.).

\subsection{CPS Energy}

San Antonio is one of the fastest growing cities in part because of the access to affordable and reliable power. CPSE serves 801,000 electrical customers and 342,000 gas customers making it the largest vertically aligned municipally owned gas and electric utility in the Nation ("CPS Energy: About Us,” n.d.). Owned by the City of San Antonio since 1942, CPSE has returned over $\$ 7$ billion dollars to the City's general fund and employs over 3,100 from the local community. CPSE's territory covers 1,566 square miles which includes all of Bexar County along with part of six others: Atascosa, Bandera, Comal, Guadalupe, Medina, Wilson, and Kendall.

The forerunner to CPSE, San Antonio Public Service Company (SAPSCo), was owned by American Light and Traction Company until 1942, when it was purchased by the City of San Antonio for \$34 million and renamed City Public Services (“CPS Energy: About Us,” n.d.). The City set up a semi-independent ownership structure through an elected five-member board of trustees, of which the Mayor of San Antonio is an ex-officio member ("CPS Energy: About Us,” n.d.). This structure allows CPSE to maintain a monopoly status while not being directly managed by or as, at least technically, part of the City. CPSE has paid back to the City on average 14\% since 1960 in lieu of taxes, accounting for \$7 billion in City revenue (CPS Energy: 2016-2017 annual report, 2017). 


\section{Current Overview}

\subsection{ERCOT}

Between 2010 and 2016, ERCOT saw steady growth, setting new demand records of over 71 GW on August 11th 2016 at 2pm ("ERCOT: About Us," n.d.). Surpassing the State of California in 2006, ERCOT became the largest wind generating state with 8,005 MW which continued to grow to $170,000 \mathrm{MW}$ installed capacity in 2016. During 2016, large-scale solar emerged doubling in size to 554 MW (“ERCOT: About Us,” n.d.). As of 2016, ERCOT serves 24 million customers, coordinates over 570 generating units, and 46,500 miles of high voltage transmission lines (“ERCOT: About Us," n.d.). Generating capacity and load is diversified across the region: Natural gas (52\%), coal (22\%), wind (20\%), nuclear (6\%) and other (1\%). Actual usage in 2016 was: Natural gas (43.7\% at 153,492,275 MWh), coal (28.8\% at $101,107,061 \mathrm{MWh})$, wind $(15.7 \%$ at 52,134,173 $\mathrm{MWh})$, nuclear $(12 \%$ at 42,090,729 MWh) and other (0.5\% at 1,699,141 MWh) (Potamac Economics, 2016).

\subsection{CPS Energy}

As a vertically aligned municipally owned monopoly utility, CPSE generates, transmits, distributes, and sells retail electricity, along with distributing and selling retail natural gas. CPSE participates in ERCOT wholesale markets, but their direct retail customers do not have choice of electric provider. Only a small portion in surrounding counties have choice in their natural gas provider.

\subsubsection{Generation}

CPSE's current generation fleet of 8,056 MW is composed of a diverse fuel mix including $13 \%$ nuclear, $27 \%$ coal, $41 \%$ gas steam, $3.7 \%$ gas turbine, $13 \%$ wind/landfill gas, and $1.7 \%$ solar (CPS Energy: 2016-2017 annual report, 2017)). Starting in 2011, CPSE invested heavily in renewable forms of electricity including wind and solar as part of their New Energy Economy and shifted away from a future of traditional fossil fuels. In 2012, CPSE purchased the Rio Nogales Power Station, an 800 MW gas combined cycle plant to replace generation capacity loss of 817 MW from the Deely Power Station shutdown planned in 2018 (Druzin, 2017). With a goal of having $20 \%$ of actual generation from renewables by 2020, CPSE has developed several partnerships to build and purchase a total of 1,059 MW of wind in North and East Texas, making it the largest municipal purchaser in the Nation (San Antonio City Public Service (CPS Energy) renewable portfolio goal, 2014). CPSE generates $500 \mathrm{MW}$ of solar power at multiple farms across the State making it the largest solar generator in Texas and the seventh largest in the Nation (Vaughan, 2015).

\subsubsection{System Infrastructure Electrical}

CPSE has over 7,866 miles of overhead and 5,476 miles of underground electrical distribution lines. CPSE's reliability rate is SAIDI 57.401, the average length of electrical power outage, and a SAIFI of 0.802, the average frequency of electric power outages, puts CPSE roughly in the top quartile of benchmarked utilities (CPS Energy: 2016-2017 annual report, 2017). CPSE owns and maintains 1,530 miles of transmission lines. These high 
voltage lines carry electricity from large-scale generation to sub-stations at local levels that step-down voltage for distribution. Three main transmission lines make CPSE's Grid, one running from the South Texas Power Project in Bay City to San Antonio and two loops encircling the City (CPS Energy: 2016-2017 annual report, 2017).

\subsubsection{Retail Sales Electric}

In 2016, CPSE had 804,675 electrical customers totaling 27.1 TWh of electrical sales and a peak demand on August 12, 2016 of 5,017 MW. Total retail electrical revenue was \$2.1 billion in FY2016 (February 1st, 2016 to January 31st, 2017), which was up \$35 million from FY2015 (CPS Energy: 2016-2017 annual report, 2017). CPSE has a variety of rate schedules depending on the amount of usage and type of organization. Each classification has a unique electrical rate schedule and service availability charge based upon the MWh used. Residential retail rates in 2016 were $\$ 0.0691$ per $\mathrm{KWh}$, with a $\$ 0.0198$ KWh surface during peak capacity and an \$8.75 service availability charge (“CPS Energy: Rates,” 2017). CPSE used a fuel adjustment charge to recover high generation fuel costs, such as gas and coal; along with funding renewable generation or purchases from the open market. Regulatory adjustment factors are also charged to residential customer to fund ERCOT, NERC, and other regulatory requirements (“CPS Energy: Rates," 2017). Both the fuel surcharge and regulatory adjustment are pass through costs, meaning that CPSE does not profit off their collection.

CPSE has several programs customers may participate in given their individual situation. Residential Energy Assistance Program (REAP) is a non-profit program that assists low-income customers afford their energy (gas and electric) bill. Funded by donations from other CPSE customers, a portion of base electric bills, and CPSE sponsored fundraisers, REAP gave away \$1 million dollars in 2016 (CPS Energy: 2016-2017 annual report, 2017). Other programs such as Home Thermostat, Demand Response, and Casa Verde are aimed at reducing utility bills through energy efficiency. These programs support CPSE's commitment to the community and off set peak energy demand by 59 MW in 2016.

CPSE provides support for their customers in two major ways. First, Customer Engineering works with customers that are requesting service or distribution lines be built or altered due to new construction of changes to current usage ("CPS Energy: Developers and Builders," 2017). These requests require a CPSE engineer to design the proposed changes to the distribution system and coordinate the construction or alteration with CPSE crews or an approved contractor. Funding for the construction or alterations is usually paid by the requesting group, but in some circumstances, is paid by CPSE due to economic benefit to the community.

Secondly, CPSE supports retail customers with their Customer Success department which handles new service, change of service, and billing questions. In 2016, CPSE launched their online portal, Manage My Account Portal, which supports more than one million transactions in their walk-in centers, and over three million calls to their Customer Contact center each year (CPS Energy: 2016-2017 annual report, 2017). 


\section{Financial Integrity}

Financial integrity has been a critical part CPSE's success over the last hundred years. The ability to have enough liquidity to cover normal operations and maintenance costs, unexpected catastrophic events (like Hurricane Harvey), and large-scale capital investments are an essential part to maintaining some of the lowest rates in the Nation. In 2016, CPSE's was rated AA+ for Senior Liens allowing the Utility to fund its large capital projects with relative low interest rates which in turn drove down overall costs and electrical rates. Access to low rate capital is a key element in their strategic plans to shift from traditional generation techniques to distributive and green technologies. Non-pass through revenues are used first to cover operations and maintenance, then debt servicing, repair and replacement funds, and payments to their respective cities. As a non-profit, CPSE applies their excess funds to repair and replacement accounts which support cash on hand and liquidity in case of major catastrophes.

\subsection{Revenue, Operation Costs, and Debt Servicing}

In FY2017 (February 1, 2016 through January 31, 2017) CPSE’s total revenue was \$2.504 billion, with $\$ 2.299$ billion coming from retail and wholesale electrical sales, \$165 million from gas sales, and \$39 million from nonoperational income (CPS Energy: 2016-2017 annual report, 2017). Total revenue dropped $1.1 \%$ for $\$ 27$ million compared to FY2016, primarily due to lower retail and wholesale electric sales. The lower revenue was offset by a lower fuel cost, a pass-through charge, of \$751 million in FY2017 compared to \$789 million in FY2016 (CPS Energy: 2016-2017 annual report, 2017). Total revenue has consistently remained around \$2.5 billion from FY2014-FY2017, reaching a peak in FY2015 at \$2.7 billion.

CPSE spends approximately $60 \%$ of revenues on operations and maintenance, $16 \%$ on debt requirements, $13 \%$ for City payment, and $11 \%$ to fund repairs and replacements. The only significant increase in cost from FY2016 to FY2017 was a 43\% pension increase, totaling \$32.5 million, to meet new financial funding requirements (CPS Energy: 2016-2017 annual report, 2017). Even with this additional expense, CPSE was able to decrease their operations and maintenance expenses, and increase their average revenue per kWh by $\$ 0.06$ to $\$ 10.75$. These increases in revenue per $\mathrm{kWh}$ helped offset the potential lost revenue due to decreased electrical sales over the last two years.

\section{Outlook}

\subsection{Distributed Energy Resources (DER)}

The smartphone didn't just connect people across the globe, it has created a newly empowered customer that expects to have control, choice, and information at their fingertips. The shift from passive to active consumerism has turned entire industries upside down and created entirely new markets. In the same way that Uber has turned every driver on the road into a potential transportation mogul, so is DER making every roof, garage, and electric vehicle owner its own power company. The decentralizing impact of DER is shifting control and profits away from large utilities and putting them in the hands of customers and small providers. DER are technologies which allow the distributed management of electrical usage 
either through distributed energy generation (DG) or distributed energy storage (DS). While they can be centrally managed and controlled, their lower cost and size allow them to be owned and operated by small companies and enterprising customers.

The most common form of distributive generation in Texas is photovoltaics (PV) solar panels. These panels convert sunlight into electricity through semiconducting materials. Once considered too costly to be practical for large-scale production, China's significant investment in PV manufacturing and adoption in the last five years has led to a significant decline in cost. With cost dropping from \$3.80/watt in 2008 to \$0.86/watt in 2012 and total installed cost around $\$ 5 /$ watt, solar power is competitive against traditional utility generation (Chapa, 2017). Lower costs and increased capital options through third party financial groups have made rooftop PV economically feasible for a greater portion of customers, especially in the hill country of Texas which has approximately 270 days of sun a year. With new technologies such as Tesla's Solar Roof hitting the market, outlook for distributed PV generation is rising at an exponential rate.

PV's greatest weakness is that it only generates electricity when the sun is shining, but most consumers need electricity around the clock (Chapa, 2017). This is where the other side of DER steps into place, DS. Storage devices such as Tesla's Wall batteries, and electric vehicles allow individual consumers to store excess generation during peak hours to be utilized when needed (Kind, 2013). Even if a customer does not have DG, in areas with time of use rates storage allows them to purchase electricity during cheaper parts of the day to utilize during peak hours, decreasing their costs. Currently, DS economic equation is not as positive as DG, but as DG becomes more common there will be more investment in DS technology increasing its viability.

CPSE is a recognized industry leader in adopting new technologies to provide their customers with personalized options and decrease their environmental impact. Starting in 2011 with their New Energy Economy (NEE) CPSE partnered with local businesses to innovate around clean energy, new technology, and energy efficiency in a move to be "unapologetically aggressive” in energy innovation (Anderson, 2015). The NEE partners committed over \$23 million to support local programs, targeted the creation of 900 San Antonio jobs, and investments over $\$ 200$ million in the local community (Martin, 2013). The NEE directly added 788 jobs as of July 2015 and $\$ 1.2$ billion in economic impact to the City of San Antonio and is projected to provide $\$ 1.4$ billion of economic benefit annually by 2019 (Anderson, 2015). All this work is being done to reach their goal of making renewable clean energy 20\% of generation and reduce carbon emissions by tens of thousands of tons by 2020 .

Through their NEE, CPSE has also invested in DG programs, working to find value streams that will offset their lost generation revenue. Their SolarHost pilot program, started in 2015 through a partnership with PowerFin, allows customers to apply to "host" a solar panel owned by CPSE on their roof in return for credits to their bill ("SolarHost San Antonio," 2015). Looking beyond the roof, CPSE’s Roofless Solar program in partnership with Clean Energy Collective allows customers to buy the rights for panels at a solar farm location, generating 1.2 MW. CPSE's customer owned solar programs allow DG to “sell” back unused 
electricity for credits to off-set their bill. Their efforts to encourage PV deployment at both the DG and utility levels have made CPSE the 7th largest solar generator in the Nation and the largest in Texas.

CPSE's President and CEO Paula Gold-Williams is looking beyond 2020 and the NEE to the Smart City, a collaborative market and technological space that allows businesses and customers to facilitate growth. CPSE does not see itself as the owner of the Smart City, but, instead, as an enabler. Their goal is to provide the space and means to encourage DER growth allowing customers access to meet their needs while providing CPSE with new streams of revenue to off-set lower demand. The partnership approach allows CPSE to provide for customers while minimizing their own financial risk.

\subsection{Energy Efficiency and Demand Response Forces (EE/DR)}

DG disrupts the supply side of the electrical industry as it provides options for customers to generate or displace time demands, as opposed to energy efficiencies (EE) and demand response (DR) forces that decrease the demand side of the equation (Kind, 2013). EE programs are designed to decrease the overall amount of electrical demand base load a customer has through changes in behaviors, technology, or engineering (Wang et al., 2015). Examples include switching to LED lightbulbs that use 70\% less electricity, weatherization of homes to decrease cooling and heating loss, and improved appliance technology. DR is designed to decrease demand during specific "peak demand" based upon overall system load requirements, or peak pricing indicators (Kind, 2013). For example, some smart thermostats allow utilities to alter internal room temperatures a few degrees to offset peak load, instead of having to turn on or purchase more costly power. Other EE/DR techniques include communication and marketing to change behaviors, or the ability to shut off non-essential appliances such as a clothes dryer.

Utilities began to heavily invest in EE/DR programs during the late 1990's as the social conscious around environmental impact increased. Initially spurred by regulatory requirements to invest in such programs, many utilities identified value propositions for EE/DR programs by being able to off-set the construction of large-scale, high risk base load generation facilities (Wang et al., 2015). Similar to checkout lines at large department stores, by minimizing base load and leveling peak load, utilities could invest in capital projects other than increased generation (Assessing Austin Energy's energy efficiency and demand response potential through 2024, 2014).

CPSE uses education and incentives to encourage EE/DR programs. As part of San Antonio's' Vision 2020, CPSE has a goal of saving 771 MW from 2009 to 2020 through EE/DR programs. Their Save for Tomorrow Energy Program (STEP) totals \$849 million and utilizes financial incentives, social engagement, and education to lower energy consumption (CPS Energy: 2016-2017 annual report, 2017). A major tool being added to CPSE's kit is their smart meter deployment, which began in 2015, and will allow for greater demand details and customer control.

Education of customers is CPSE's first tactic in implementing EE/DR programs. Utilizing 
targeted local media outlets, CPSE leaders educate the community on EE opportunities and best-practices. Partnering with local schools, CPSE provides educational aids to students and educators to learn about the electrical grid and ways savings may be obtained through the School2Home program (“CPS Energy: Energy efficiency programs,” 2017). Utilizing smart meter technology, customers get personalized consumption data and comparison data with tips on how to conserve and reduce consumption. CPSE added the human touch by developing their customer contact personnel as Energy Advisors (EA) which support customer's transactional needs, while simultaneously informing them of individualized EE/DR programs.

CPSE's second tactic in encouraging EE/DR implementation is through incentives. Casa Verde, part of CPSE's Save Now program, provides free weatherization for qualifying customers. On average, each qualifying customer receives nearly \$5,000 in EE upgrades ranging from insulation, air sealing, and LED replacement ("CPS Energy: Energy efficiency programs,” 2017). Even for customers who don’t qualify for Casa Verde, CPSE offers rebates on appliance upgrades such as pool pumps and A/C units, and instore rebates on LEDs and energy star equipment. CPSE offers rebates on maintaining or updating $A / C$ units as they account for $60 \%$ of peak demand. Smart thermostat programs, such as Nest's Rush, offer a \$30/year rebate for allowing CPSE to raise temperate of 2-3 degrees during peak demand, offsetting $42 \mathrm{MW}$ (DR CPSE).

CPSE's education and incentive approach has facilitated a 411 MW cut since 2009 moving towards their $711 \mathrm{MW}$ goal in 2020. As CPSE looks beyond 2020, they face new challenges for their EE/DR programs as the quick wins around early adopters in LED lighting and smart thermostats have been captured.

\section{Analysis of Position}

CPSE is the largest municipally owned energy utility in the Nation because of their ability to provide exceptional value to the City of San Antonio to the tune of $\$ 7.3$ billion over the last 75 years while continuing to provide the second lowest average energy bills of the 10 largest cities in the US. This history of consistent success is potentially troublesome as new disruptive forces apply pressure to an entrenched institution to change rapidly. CPSE faces four significant risks in their attempt to address the disruptive forces: 1) an aging, diversified generation fleet, 2) unbalanced cost recovery for distribution improvements and repairs, 3) attraction and retention of human capital in key positions, and 4) threat of new, external competition, especially in commercial markets. Although each of these risks has the potential to negatively impact future performance, all four areas also provide specific opportunities to target focused efforts in an ever-changing industry.

CPSE's diversification in the 1980's and 1990's helped them maintain low rates while volatile fuel commodities, specifically natural gas, prices pushed rates up Nationwide. That diversification now is a hindrance as the pendulum has swung and fracking technology has resulted in historically low natural gas prices. Which stranded a significant amount of long term investment in large coal generation facilities which are currently not economical on open whole-sale markets. Early investment in the STP project gave CPSE consistent, 
inexpensive base load, but the write off \$351 million in 2014 of the Unit 3 \& 4 project, along with an uncertain nuclear future puts a large portion of their base load at risk. At the same time, it gives CPSE the opportunity to invest in other new generation technology and DG while minimizing their lost sunk costs. As their plants are decommissioned they can shift capital expenditures to more cutting-edge technology or purchase power agreements with shorter return on investment times and less volatile operations costs.

Not only is their generation fleet aging, but CPSE's transmission and distribution networks are requiring more investment and repairs annually due to growth and the strain put on infrastructure through DG. Rate structure is based primarily on usage rates and low access fees, but DG and EE/DR forces are decreasing demand growth while increase distribution costs, leading to an unbalanced cost recovery. There is an opportunity, upgrading of the distribution and transmission systems gives CPSE the chance to capitalize activities that historically would be considered O\&M by replacing older technology with more modern automated options. These new system operations devices can then decrease the need for direct control and field personnel, opening a door for advanced AI to increase efficiencies, maintain reliability, and decrease safety risks.

Historically utilities have hired in waves, bringing on large numbers of new employees when building large generation units or big network expansion projects. The building boom of multiple plants in the 1980's created a large grouping of employees, all retirement eligible around the same time. CPSE is facing the challenge, like many other utilities, where $20-40 \%$ of their workforce is retirement eligible in the next five years. With a large portion of these being in the skilled craft and operational leadership, a group in the labor market that is getting harder to find, CPSE faces a significant knowledge crisis. President and CEO Paula Gold-Williams understands this challenge and through her People First philosophy is striving to attract new talent and create a culture of learning to minimize the risk. Positioned as a cost-based monopoly in times of slowed revenue growth however limits financial flexibility in managing this workforce shift. The large amount of retirements does allow CPSE to shift their talent pool to be aligned with the direction of technology and the industry. In a few short years, they could shift from a mature workforce, to one with greater technological competencies and lower salaries. CPSE must look to new pipelines of talent, craft a compelling public brand, and leverage job augmenting technology to overcome the exodus of talent they face.

While CPSE has some of the lowest residential rates in the State and Nation, which helps drive customer satisfaction, their large commercial customers are increasingly voicing their desires to partake directly in the ERCOT wholesale markets. Microsoft, HEB, and Walmart have all sought opportunities across the ERCOT region to buy directly from the wholesale markets to meet their State-wide needs. While State legislation to date has not revoked CPSE's monopoly status, large companies in San Antonio and across Texas are lobbying for the ability to but on the wholesale market. Wholesale competition poses risks and rewards for CPSE and the City of San Antonio. While there is a risk for loss revenue, it also opens other markets across the state and creates an opportunity for CPSE as a leader in renewable energies to develop ERCOT wide purchase power agreements with large key accounts that 
seek to offset their carbon impact through non-carbon generation.

None of these risks, individually, will determine the long-term success or failure of CPSE to continue to provide value to their customers and the City of San Antonio. Each risk: their generation fleet, distribution needs, talent turnover, and wholesale competition, can be utilized to increase their market position or value proposition. How they address these risks will matter and their position as a municipal monopoly is a constant element that runs through everything they do. While investor-owned utilities focus on stakeholder's bottom line and quarterly reports, CPSE takes a more holistic and long term approach. Ensuring they meet bond holder's expectations, and their community's needs. As Gold-Williams puts it "Our ability to focus on solely what they need and meeting the needs of what our community wants is a different ball game, even the bondholders don't drive decisions; they just want to be paid. The decisions actually happen in our community. That's the difference" (Bade, 2017).

\section{Conclusion}

The electrical industry is changing, it is facing the chaotic elements that overthrew the telecommunications and mass media giants of the 1990's and 2000's. Technology has allowed people more choice and control in their use and even creation of electrical needs. Gone are the days of constant rising demand and monopolized central generation were the company saw only rate payers and consumers. What the future holds is uncertain, but it will contain customers demanding choice and control. As the largest municipally owned energy company, CPSE must navigate the hazards with expertise if they seek to continue to provide value for their community and customers.

The disruptive forces of DER and EE/DR have forced utilities to find new business models that provide affordable and reliable power today, but are also sustainable tomorrow. CPSE is facing infrastructure choices and talent dynamics, but their diversification in generation and the natural gas business provides opportunities to decrease risk. CPSE's fate is closely tied to the political climate in Austin, Texas's capital and external pressures to allow wholesale competition can undercut their monopoly status. How CPSE responds to these forces and risks over the next five years will determine what powers the fastest growing part of Texas for the coming decades.

\section{References}

Anderson, J. (2015). CPS Energy's “New Energy Economy” pays off for San Antonio, white paper says. Public Power Daily, 2. [Online] Available: http://www.publicpower.org/Media/daily/ArticleDetail.cfm?ItemNumber=44264

Assessing Austin Energy's energy efficiency and demand response potential through 2024. (2014). Hinesburg, VT.

Bade, G. (2017). “Enabler of the smart city”: CPS Energy’s CEO on democratizing distributed energy. Utility Drive. [Online] Available: http://www.utilitydive.com/news/enabler-of-the-smart-city-cps-energys-ceo-on-democratizin 
g-distributed/440162/

Census Bureau: Quick Facts. (n.d.). [Online] Available: https://www.census.gov/quickfacts/fact/table/sanantoniocitytexas,austincitytexas/PST045216

Chapa, S. (2017). CPS Energy renews rooftop solar rebate program, commits $\$ 15 \mathrm{M}$ in new funding. San Antonio Business Journal, p. 2. San Antonio, TX.

CPS Energy: 2016-2017 annual report. (2017). San Antonio, TX.

CPS Energy: About Us. (n.d.). [Online] Available: https://www.cpsenergy.com/en/about-us.html

CPS Energy: Developers and builders. (2017). [Online] Available: https://www.cpsenergy.com/content/corporate/en/developers-builders.html

CPS Energy: Energy efficency programs. (2017).

CPS Energy: $\quad$ Rates. (2017). [Online] Available: https://www.cpsenergy.com/content/corporate/en/about-us/who-we-are/rates.html

Druzin, R. (2017). CPS Energy pursues clean energy plans despite Trump environmental order. MySA. San Antonio, TX.

ERCOT. (n.d.). History of ERCOT. [Online] Available: http://www.ercot.com/about/profile/history

FERC. Federal Energy Regulatory Commission (FERC) Order No. 2000 \& 2000A, Pub. L. No. 18 CFR PArt 35 (1999). [Online] Available: https://www.ferc.gov/legal/maj-ord-reg/land-docs/RM99-2A.pdf

Hausman, W. J., \& Neufeld, J. L. (2011). How politics, economics, and institutions shaped electric utility regulation in the United States: 1879-2009. Business History, 53(5), 723-746. http://doi.org/10.1080/00076791.2011.599589

Kim, J. (n.d.). History of FERC. [Online] Available: https://www.ferc.gov/students/ferc/history.asp

Kind, P. (2013). Distruptice challenges: Financial implications and strategic responses to a changing retail electric business. Washington, D.C.

Kwoka, J. (2008). Restructuring the U.S. electric power sector: A review of recent studies. Review of Industrial Organization, 32(3-4), 165-196. http://doi.org/10.1007/s11151-008-9171-2

Martin, L. (2013). San Antonio and the "New Energy” economy. San Antonio, TX.

Potamac Economics, L. (2016). 2015 State of the Market Report for ERCOT Wholesale Electrical Markets. New York, NY.

Saha, B. (2003). Economic Cost of the August 14, 2003 Blackout. Natural Gas \& Electricity, 20(4), 10-13. 


\section{Macrothink}

Case Studies in Business and Management

ISSN 2333-3324

2017, Vol. 4, No. 2

San Antonio City Public Service (CPS Energy) renewable portfolio goal. (2014). Washington, DC.

[Online]

Available:

https://energy.gov/savings/san-antonio-city-public-service-cps-energy-renewable-portfolio-go al

SolarHost San Antonio. (2015).

US House of Representatives. Public Utiliy Holding Company Act. (1935). Committee of Financial SErvices of the U.S. House of Representatitves. [Online] Available: https://www.sec.gov/about/laws/puhca35.pdf

Vaughan, V. (2015). San Antonio No. 7 solar power in nation. San Antonio Express News. San Antonio, TX.

Visit San Antonio. (n.d.). [Online] Available: http://visitsanantonio.com

Wang, J., Zhu, Y., \& Li, Y. (2015). EPP Energy Efficiency Calculation and Influencing Factor Analysis: Cases in China. Mathematical Problems in Engineering, 2015. http://doi.org/10.1155/2015/986562

\section{Copyright Disclaimer}

Copyright for this article is retained by the author(s), with first publication rights granted to the journal.

This is an open-access article distributed under the terms and conditions of the Creative Commons Attribution license (http://creativecommons.org/licenses/by/3.0/). 